Article

\title{
A Case Study of Familiar Gastrointestinal Pathologies at Risk of Cancer. Early Detection of Degenerative Signals by Oxidative Stress Biomarkers.
}

\author{
Carla Ferreri ${ }^{*}$, Maria Marone ${ }^{2}$, Elena Confalone ${ }^{2}$, Anna De Maio ${ }^{2}$, Chrissostomos \\ Chatgilialoglu ${ }^{1}$, and Maria Rosaria Faraone Mennella 2,* \\ 1 ISOF, Consiglio Nazionale delle Ricerche, Via P. Gobetti 101, 40129 Bologna (Italy); \\ chrys@isof.cnr.it \\ 2 Department of Biology, University of Naples “Federico II” (Italy); MM: Ma.marone@studenti.unina.it, EC: \\ confalon@unina.it, AdM: andemaio@unina.it, MRFM: faraone@unina.it* Correspondence: \\ carla.ferreri@isof.cnr.it (C.F.); faraone@unina.it; Tel.: +39081679136 (MRFM);
}

\begin{abstract}
Background: Beyond risk factors such as smoking, obesity and others, gastrointestinal cancer often occurs in families and the risk of getting cancer is passed down from parents to offspring. About $5 \%-10 \%$ of gastrointestinal cancers are hereditary (inherited by a gene mutation from one or both parents, predisposing them to develop cancer in their lifetime). Here we describe the clinical history of family members affected by gastrointestinal pathologies which often leaded to cancer. Methods: The subjects were monitored from May 2006 to December 2017 by collecting periodically clinical and endoscopic data, and performing molecular analyses by assaying two biomarkers, auto-modification of lymphocyte Poly(ADP-ribose)Polymerase as early signal of DNA damage, and erythrocyte membrane lipid composition (Fat Profile). First we focused on the oldest members, nine brothers, and thereafter we considered their offspring. Results: Both groups of subjects developed gastrointestinal pathologies of different kind and seriousness. Some diseases evolved to cancer, sometimes as a sudden and lethal event. The results of the two molecular approaches auto-modification of Poly(ADP-ribose)Polymerase and Fat Profile), were in agreement and even predicted the clinical and imaging paths. Conclusions: Both non-invasive molecular analyses can be used preliminarly to predict altered physiological states and support clinical and imaging analyses.
\end{abstract}

Keywords: cancer; DNA damage; digestive tract diseases; fat profile; lipids; Poly(ADP-ribose) Polymerase; PARP; poly(ADP-ribose); PAR

\section{Introduction}

Functional disorders are those in which the gastrointestinal (GI) tract looks normal but doesn't work properly [1]. They are the most common problems affecting the GI tract (including the colon and rectum). GI disorders include such conditions as constipation, irritable bowel syndrome, hemorrhoids, anal fissures, perianal abscesses, anal fistulas, perianal infections, diverticular diseases, colitis, colon polyps and cancer [1]. Hereditary cancer syndromes are the result of specific inherited genetic mutations that contribute to a person's lifetime risk of cancer. Sometimes, cancerpredisposing mutations are inherited giving rise to hereditary cancer syndromes [2, 3]. Almost all colorectal cancers begin as polyps, benign (non-cancerous) growths in the tissues lining the colon and rectum. Cancer develops when these polyps grow and abnormal cells develop and start to invade surrounding tissue. Most early forms of colorectal cancer do not cause symptoms, which makes screening especially important. When symptoms do occur, the cancer might already be quite advanced. Gastro-intestinal (GI) cancers remain among the most common forms of cancer worldwide 
and are an excellent model for the investigation of hereditary factors in cancer [4]. Gastro-intestinal cancer belongs to the neoplastic spectrum of hereditary non-polyposis colorectal cancer, a genetic disease with an autosomal dominant pattern of inheritance. Familial polyposis (FAP) and hereditary non-polyposis colorectal cancer (HNPCC) are the two main hereditary colon cancer syndromes [5]. Dysplasia is still today the mainstay of cancer prediction in most inflammatory disorders of the gastro-intestinal tract and is an independent marker of cancer risk. Epidemiological studies on high risk populations evidenced a strong familiarity for esophageal cancer with up to $60 \%$ of the affected patients reporting a positive familiary history [6]. The initial alterations which are not detectable on histologic examination, are subtle changes in the normal balance between cell growth and cell death. The genes responsible for these syndromes have recently been identified; as a result, genetic testing has become the most important determining factor in clinical decisions. Infact with current diagnostic and clinical approaches the prognosis of gastric cancer is very poor. Similar to other solid cancers, GI, in particular gastric cancer, is a complex disease resulting from combinatorial interactions among diverse factors including environmental, host-genetic and molecular mechanisms. For instance, persistent infection of the gastric mucosa by Helicobacter pylori can initiate an inflammatory cascade that progresses into atrophic gastritis, a condition associated with reduced capacity for secretion of gastric acid and an increased risk of developing gastric cancer [7]. H. pylori infection promotes gastric cell death and reduced epithelial cell turnover in the majority of infected cells, resulting in primary tissue lesions associated with an initial inflammatory response [8]. The role of $H$. pylori infection in early stages of gastric carcinogenesis is to increase the incidence of precancerous lesions [8]. GI cancers arise in part because of disruption of cell death mechanisms including apoptosis that contributes to cell expansion. Altered expression of cell cycle/apoptosis key regulators may promote tumor progression, reflect secondary genetic/epigenetic events, and impair the effectiveness of therapy [9]. A key enzyme in the apoptotic process of cells is poly-ADP-ribose polymerase (PARP), the specific target of caspase 3 [10]. PARP is a multifaceted enzyme that through its product poly(ADP-ribose) is directly involved in the regulation of chromatin architecture and functions, with a main and prevalent role in DNA repair [11-13]. The synthesis of the polyanion poly(ADP-ribose) by the nuclear PARP 1, the main member of PARP family, starts after the first ADP-ribose unit has been transferred from $\mathrm{NAD}^{+}$to an acceptor protein [14]. The transition from modified to unmodified targets is granted by poly(ADPribose) glycohydrolase, that shuttles from cytoplasm to nuclei and viceversa [15]. This enzyme degrades the polymer with both endo- and esoglycosidic activity. PARP activation provides a rapid, post-translational signal that can halt the transcription and replication machineries and mobilize DNA repair apparatus. When the DNA of a cell is damaged at low level, the cell will activate mechanisms to arrest the cell cycle and repair the DNA lesions [16]. If the level of DNA damage is very high, the cell will activate the process of death (apoptosis or necrosis). Inhability of cell to undergo apoptosis results in cancer and autoimmune diseases [17, 18]. PARP1 has a main role in DNA damage signaling and cell death pathways [16]: the equilibrium between specific pathways and the local cellular environment leads to the net result, such as proliferation or terminal differentiation, survival or cell death $[16,18]$. On the basis of these data, cell cycle/apoptosis maintenance is considered instrumental for optimal therapy response. Given the role of PARP as biomarker of DNA damage in pre-apoptotic and apoptotic events, and its recognized importance as a signal of oxidative stress, it is conceivable that its activity levels/expression in the cell nucleus can help in defining the cellular physio-pathological state.

Another cell feature able to give information at molecular level is the membrane lipid composition [19]. In general lipidomics describes and quantitatively analyses the full complement of lipids in the human body (body fluids, cells, tissues), and integrates these data with knowledge of their protein targets, i.e. the metabolic enzymes and transporters, and of the relevant genes and the regulatory aspects of these physiological systems [19]. Lipids are the building blocks of cell membranes, providing them with a homeostatic system through their physical characteristics as well as with their reactivity due to the unsaturated fatty acid residues. An understanding of cell membranes is only possible with a comprehensive understanding of their lipid constituents [20]. The 
cell membrane is highly organized and extremely important for a correct performance of the functions of the cell; it is a sensor that changes and adapts continuously to metabolic stimuli and the external environment (diet, stress, physical and chemical agents) and the fatty acid (FA) composition has a predominant role for this accomplishment. The membrane FA asset, i.e., saturated (SFA), monounsaturated (MUFA) and polyunsaturated (PUFA) FAs, present in the phospholipids is characteristic of each tissue [19-21]. A natural adaptation response is active and the appropriate changes of the FAs microenvironment ensure the best functioning of membrane proteins, receptors, pumps and signals in tissues, according to environmental and metabolic needs [22].The important role of changes to the membrane structure and corresponding physical-chemical properties are well established [23]. A recent report gave evidence that PARP-1 ablation alters eicosanoid and docosanoid signaling and metabolism in a murine model of contact hypersensitivity [24]. Moreover both molecular events drive epigenetic mechanisms [25]. These observations highlight that PARP automodification (PAR-PARP) and membrane fatty acid composition (Fat Profile) are molecular aspects which can be taken together as complementary information of the healthy/pathological state of the cell. In fact each of the two have been independently used by authors to look at membrane status and DNA damage in the cell $[26,27]$. We have previously reported a direct correlation on the parallel and synergic involvement of two crucial cell compartments, nucleus and membrane, to build up an integrated panel for evaluating cell molecular health [28]. This possibly preventive strategy can utilize both biomarkers in order to stratify cancer patients into appropriate screening or surveillance programs; the combination of non invasive both PARP test and lipidomic analysis on blood samples as biomarkers has been helpful in different pathologies, beside cancer [28]. Here we report a case study of familiar predisposition to GI pathologies often changed into cancer, that was early predicted and later followed up by the combination of the two analyses.

\section{Results and Discussion}

The survey began on 2006 and went on up to 2017 for old and young people. To simplify the description of the results, we initially discuss about the elderly members of the family, nine brothers, which the largest number of information was available for. Afterwards, the clinical pictures of some of the youngest family members are evaluated.

\subsection{Anamnestic and clinical data of the family's elderly members}

The parents of the nine brothers had deceased for acute myocardial infarction (father) and ischemic stroke (mother). No further information about their general status was available.

Table 1 shows the anamnesis of the nine brothers at beginning of the survey (2006). At time of the first interview, most family members were already affected by GI pathologies. The presence of apparently non-cancerous gastro-enteric diseases was common quite to all, except to subjects 1 and 5 (Table 1). Before the survey, on 1999, one of the sisters had undergone gastric resection following cancer evolution of previous gastritis, still suffering of intestinal inflammations and being under therapy (Table 1, patient $\mathrm{N}^{\circ}$ 7).

Subject 4 had already died before the investigation (on 2003) and here information collected from relatives is reported. He was enclosed to get a complete picture of all brothers' medical histories, and in a next section, of his children. All the eight alive subjects in Table 1 underwent to a careful family and personal history interview, accompanied by the results of common clinical analyzes and general information on their lifestyle. They worked in different fields and lived in the same geographical area, had very similar lifestyles, without excess of smoke and alcohol, and common diet habits due to the presence in the territory of cultivations and breeding of typical products of the Mediterranean diet.

H. pylori, an important hallmark in gastrointestinal disorders, which occurs in the most advanced stages of the pathologies, initially, was negative for all the brothers (Table 1). 
Table 1. Main Anamnestic Data of Brothers, starting the survey on 2006.

\begin{tabular}{|c|c|c|c|c|c|}
\hline Subject ${ }^{1} \mathbf{N}^{\circ}$ & $\begin{array}{c}\text { Age/ } \\
\text { gender }\end{array}$ & Job & GE Desease/ Surgery & $\begin{array}{l}\text { Other Deseases/ } \\
\text { Surgery }\end{array}$ & H. pylori \\
\hline 1 & $69, \mathrm{~F}$ & Postal Clerk & None & Cholecystectomy Hypertension & No \\
\hline 2 & $66, \mathrm{M}$ & Unemployed & $\begin{array}{l}\text { Diverticulosis,rectal/ sigmoidal } \\
\text { polyposis, hiatal hernia }\end{array}$ & Meningitis & No \\
\hline 3 & $63, \mathrm{~F}$ & Postal Clerk & $\begin{array}{c}\text { Diverticulitis, rectal/ sigmoidal } \\
\text { polyposis }\end{array}$ & None & No \\
\hline $4^{+}$ & $59, \mathrm{M}$ & Postal Clerk & Diverticulitis & $\begin{array}{l}\text { Hypertension,adrenal adenoma, } \\
\text { Hypercholesterolemia, } \\
\text { epindemoma with lateral } \\
\text { hematoma }\end{array}$ & Not available \\
\hline 5 & $60, \mathrm{~F}$ & Farmer & None & $\begin{array}{l}\text { Hypertension, } \\
\text { Hypercholesterolemia }\end{array}$ & No \\
\hline 6 & $58, \mathrm{~F}$ & Housekeeper & Diverticulitis & Surgery at the Botallo duct & No \\
\hline 7 & $50, \mathrm{~F}$ & Dealer & $\begin{array}{l}\text { Hemorrhoidal } \\
\text { Thrombophlebitis, } \\
\text { Gastrectomy }\end{array}$ & Hypercholesterolemia & No \\
\hline 8 & $52, \mathrm{M}$ & Railroader & Esophagitis, hiatal hernia & $\begin{array}{c}\text { Cholecystectomy,Carotid } \\
\text { plaques }\end{array}$ & No \\
\hline 9 & $54, \mathrm{~F}$ & Railroader & $\begin{array}{l}\text { Diverticulitis,intestinal } \\
\text { adhesions }\end{array}$ & None & No \\
\hline
\end{tabular}

1Parents deceased by: ischemic stroke (mother); acute myocardial infarction (father)

$\mathrm{M}$, male; F, female. 
Hyperthension and high levels of hematic cholesterol were frequent clinic symptoms among brothers, suggesting familiar predisposition to cardiovascular pathologies too (Table S1 in Supplementary Material).

The predisposition to gastro-intestinal pathologies with clear evolutions towards tumors required, over the years, a close surveillance of these subjects with periodic (every three-six months) endoscopies (gastro- and colonoscopy). Despite the periodic analyzes, endoscopies did not allow a diagnosis of serious pathology before morphological alterations of the tissue occurred. Hence the need to study whether any molecular marker could allow an earlier diagnosis, before tissue degeneration occurred.

\subsection{Poly(ADP-ribose) polymerase auto modification (PAR-PARP) in lymphocyte lysates of elderly family members.}

Controls and family members were subjected to the first molecular investigation with the measure of the hyper-modification of PARP (abbreviated PAR-PARP).

After electrophoresis and western blotting, the blotted proteins $(20 \mu \mathrm{g})$ were analyzed with antiPARP catalytic site antibodies.

In Supplementary Material ( $\S$ S2.2.1) the method of densitometric measures and interpretation of data is described, with a scheme of immunopattern (Figure S1). The results of PAR-PARP densitometric analysis obtained for the controls are reported too (§ S2.2.2, and Figure S2).

2.2.1. First PAR-PARP analysis in lymphocyte lysates of elderly family members. Immunological and densitometry profiles.

PAR-PARP already proved to be a good indicator of DNA damage measurable from physiological to massive levels [28].

Figure 1 (A) shows the immunological profiles of subjects 1-3 and 5-9 of Table 1. In a previous paper we already evidenced that PARP 2 is particularly abundant in lymphocyte lysates and that the measured PAR-PARP enclosed also automodification of PARP $2[27,28]$.
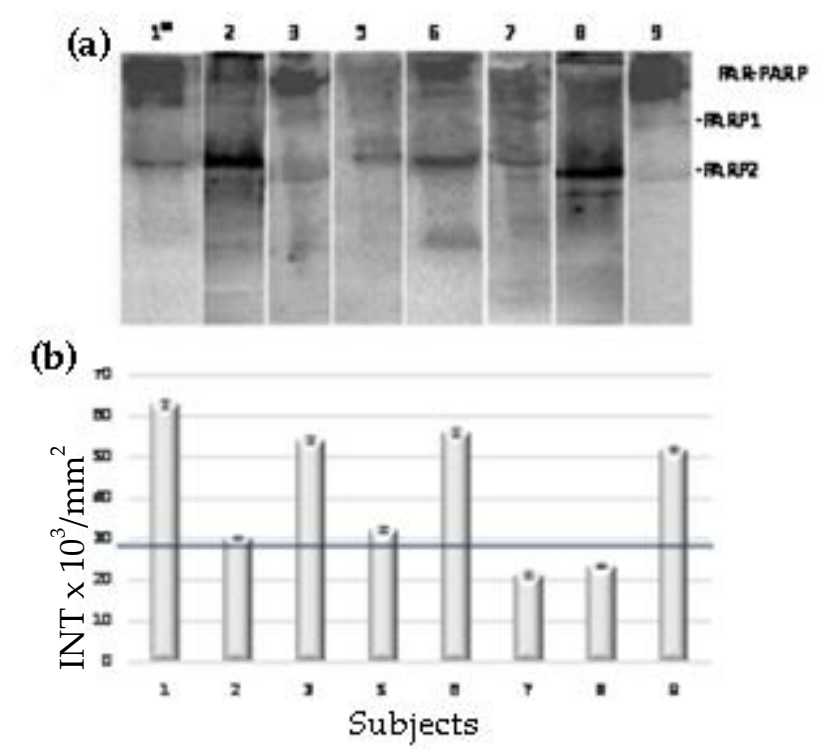

Figure 1. (a) Anti-PARP Immunopatterns of brothers' lymphocyte lysates, on 2006. (b) Densitometries of PAR-PARP of samples in panel (a). The numbers correspond to subjects of Table 1. The black line is the control cut-off (§ 2.2.2S, Figure $2 S$ ). Ranges of PAR-PARP variability corresponding to different levels of DNA damage are reported in the legend to Figure 2S. 
The molecular analysis of the brothers' lymphocytes clearly showed that, compared to the controls, samples had from moderate to very high levels of modified PARP, corresponding to DNA damage of different degrees [28].

The densitometric analysis of PAR-PARP bands allowed to quantify hypermodification levels (Figure 1, b). For subjects 2, 7 and 8 the values were within those of controls, below the upper limit for 7 and 8 , and for subject 2, very close to cut-off. The endoscopies of these subjects were all negative for cancer, even if the subject 2 declared gastroenterical pathologies and the subject 7 had already been submitted to gastrectomy. In the latter case, PAR-PARP is at physiological levels probably because DNA damage was mainly resolved with surgery and subsequent therapy.

It is worth noting that sister 1, not declaring any diseases, showed the highest PAR-PARP value, corresponding to massive DNA damage.

Similarly, very high was PARP hypermodification of subject 3 in the absence of cancer endoscopic diagnoses In the latter two cases, especially in 1, the molecular analysis suggested a nonphysiological condition which did not correspond to a macroscopic tissue alteration, as indicated by the negative clinical and endoscopic reports provided by the subjects. In particular, subjects 3, 6 and 9 who declared gastrointestinal diseases showed PAR-PARP levels among the highest ones.

\subsubsection{Second PAR-PARP analysis of elderly members.}

On 2009 a second molecular analysis was carried out and further information was collected to update the situation of the brothers.

Figure 2 shows, in comparison, the PAR-PARP values of Figure 1 (B), and those determined on 2009.

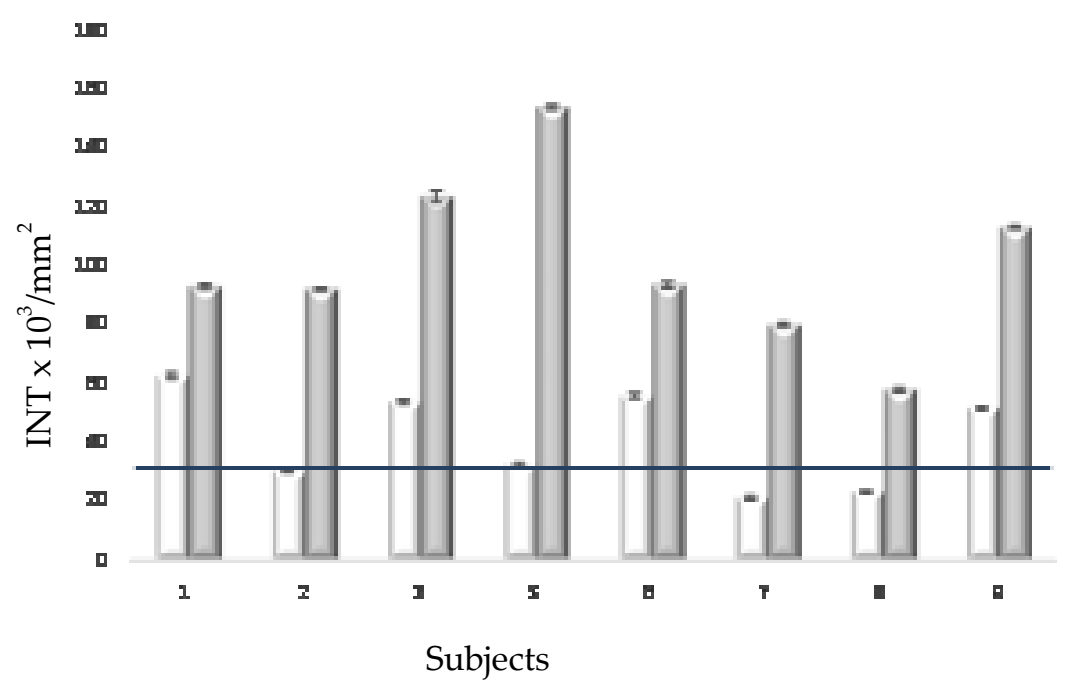

Figure 2. Comparison of PAR-PARP analysis of brothers' lymphocyte lysates starting the survey (2006, white) and on 2009 (grey). The numbers correspond to subjects of Table 1. The black line is the control cut-off. Ranges of PAR-PARP variability corresponding to different levels of DNA damage are reported in §S2.2.1 (Supplementary Material). Immunoblotting patterns of the second analysyis (grey) in Figure S3.

The level of hypermodification of PARP is considerably increased for all subjects, highly above the cut-off. Except for subject 8 for which densitometry is still in the range of moderate damage, all others show values corresponding to very high DNA damage. For subjects 1-3, 5, 7, 8 and 9, densitometry measures were two to five times higher than in the first analysis. This group included both subjects who did not declare diseases of the digestive system $\left(\mathrm{N}^{\circ} 1, \mathrm{~N}^{\circ} 5\right)$, and those with gastroenteric diseases of various kinds, especially diverticulosis and diverticulitis. 


\subsection{Erythrocyte membrane fatty acid (FA) analysis (Fat Profile ${ }^{\circledR}$ ) of elderly members}

The erythrocyte membrane has a characteristic FA asset; all FAs are present in specific amounts in the phospholipids of the bilayer. The response of lipid analysis, considered herein, is the FAT PROFILE $®$ (more details in Supplementary Material, §S2.3). In particular we focused our attention to the FAs which are mostly involved in inflammatory pathways, either as pro- $(n 6 \mathrm{FA})$, and anti ( $n 3$ FA)-inflammatory mediators [23]. Therefore the $n$ (omega)-6 DGLA and ARA, the $n$ (omega)-3 EPA and DHA were mainly considered in this study.

As an example, the Fat Profiles of old subjects are reported in Table 3S (Supplementary Material). The pro-inflammatory pathway leading to DGLA as precursor of ARA is altered for all subjects, being above the upper normal limit (2.4). Nevertheless the levels of ARA result in the range of normality or lower. An explanation is that DGLA is also precursor of prostaglandins (PG) which inhibit inflammation and favor the immune response, therefore its increase can be correlated to cell protection [21]. Signals of an inflammatory condition are the low levels of antioxidants $n 3$, DHA and EPA, for all subjects highly below the lowest normal value. Calculating the $n 6 / n 3$ ratios they are in favour of pro-inflammatory compounds.

Table 2 shows in comparison, the unbalance (\%) of pro- inflammatory ( $n 6 \mathrm{FA})$, and antiinflammatory ( $n 3 \mathrm{FA}$ ) mediators measured in the two analyses.. 
Table 2. Comparison of pro and anti inflammatory PUFAs unbalance (\%) from Fat Profiles of the elderly members (years 2006 and 2009).

\begin{tabular}{|c|c|c|c|c|c|c|c|c|c|c|c|c|c|c|c|c|}
\hline \multirow{3}{*}{$\begin{array}{l}\text { FATTY } \\
\text { ACIDS } \\
\text { Linoleic }\end{array}$} & \multicolumn{16}{|c|}{ UNBALANCE $\%^{\mathrm{a}}$} \\
\hline & \multicolumn{2}{|c|}{1} & & \multicolumn{3}{|c|}{2} & \multicolumn{5}{|c|}{3} & \multicolumn{3}{|c|}{5} & \multirow{2}{*}{$\frac{\text { Brother }}{0}$} \\
\hline & 0 & 0 & 0 & 0 & $0^{9}$ & 0 & 0 & 0 & 0 & 0 & 0 & 0 & -1.1 & -1.1 & +0.22 & \\
\hline DGLA & +1.1 & -5.3 & +0.72 & +12.5 & +1.2 & 0 & +0.2 & -5.26 & $\begin{array}{c}+0.3 \\
1\end{array}$ & 0 & +0.4 & -15.8 & 0 & 0 & +0.46 & -10.5 \\
\hline ARA & 0 & +18 & +0.38 & +19.4 & 0 & +4.7 & 0 & +9.4 & -1.25 & +5.9 & -0.28 & +0.59 & +16.5 & +16.5 & 0.0 & +3.5 \\
\hline EPA & -38 & 0 & -16 & -20 & -18 & -20 & -34 & -20 & -54 & -20 & -24 & 0 & -26 & 0 & -34 & -20 \\
\hline DHA & -36 & 0 & -12 & 0 & -16 & -6 & -30 & -16 & -48 & -18 & -30 & -2 & -28 & +4.3 & -45 & -4 \\
\hline $\mathrm{n} 6 / \mathrm{n} 3^{* *}$ & 13 & 5.5 & 5.8 & 6.0 & 6.1 & 6.6 & 7.8 & 7.5 & 10.3 & 7.2 & 6.8 & 5.9 & 7.0 & 3.9 & 10.7 & 6.0 \\
\hline
\end{tabular}

Abbreviations: ARA, arachidonic acid (5,8,11,14-eicosatetraenoic acid); DGLA, Dihomo-gamma-linolenic acid (8,11,14eicosatrienoic acid); DHA, Docosahexaenoic acid; EPA, Eicosapentaenoic acid.

${ }^{a}$ Unbalance \%: The percentage of FA variation above or below the normal range: $(+)$, increased value (above upper limit), $(-)$, reduced value. (below lower limit).

** n6/n3 ratio normal range: $3.5-5.5$ 
A common feature of the first FAT Profile (2006, values on the left) of all brothers was the high deficiency of $n 3$ FA (EPA, DHA), which indicated a high inflammatory status and splitted $n 6 / n 3$ ratios above the normal range, despite the levels of ARA were normal or slightly above the normal range (Table 2). One exception was for subject $N^{\circ}$ 9, who showed a great ARA increase.

The results of second analysis (2009, values on the right), showed a high reduction of $n 6 / n 3$ ratio for subjects 1-6-7-8-9, apparently in favour of an anti-inflammatory condition. Looking at the relative unbalance of $n 6$ and $n 3$ compounds, it is evident that the lack of n3 FA is still relevant and the ratio is influenced (reduced) by any increase of n6 compounds.

In other subjects the $n 6 / n 3$ ratios of both analyses were always above the normal range suggesting that the inflammatory condition still occurred on 2009 and was general for all subjects.

\subsection{Follow up of brothers' GI pathologies.}

From 2009 to 2017, the clinical condition of some subjects underwent a further, sometimes lethal evolution.Table 3 shows the update of the pathological history of the brothers up to 2017. 
Table 3. Clinical Data of Brothers. Follow up compared wih first diagnoses.

\begin{tabular}{|c|c|c|c|c|c|}
\hline Subject* $\mathbf{N}^{\circ}$ & $\begin{array}{l}\text { Age/ } \\
\text { gender }\end{array}$ & $\begin{array}{l}\text { GE Disease } \\
\text { Surgery (2006) }\end{array}$ & $\begin{array}{l}\text { H. Pylori } \\
(2006)\end{array}$ & $\begin{array}{l}\text { Follow-up GE } \\
\text { Disease/ Surgery }\end{array}$ & $\begin{array}{l}\text { Follow-up } \\
\text { H.pylori }\end{array}$ \\
\hline 1 & $69, \mathrm{~F}$ & None & No & $\begin{array}{l}\text { Foveolar hyperplasia and intestinal } \\
\text { metaplasia }\end{array}$ & Positive \\
\hline 2 & $66, \mathrm{M}$ & $\begin{array}{l}\text { Diverticulosis, rectal/ sigmoidal } \\
\text { polyposis, hiatal hernia }\end{array}$ & No & $\begin{array}{l}\text { Pancreatic head cancer and death within } \\
\text { six months of being diagnosed with } \\
\text { cancer }\end{array}$ & Positive \\
\hline 5 & $60, \mathrm{~F}$ & None & No & Gastric mucosa dysplasia & Positive \\
\hline 6 & $58, \mathrm{~F}$ & Diverticulitis & No & Breast cancer followed by colon cancer & Positive \\
\hline 9 & $54, \mathrm{~F}$ & Diverticulitis, intestinal adhesions & No & Gastrectomy & Negative \\
\hline
\end{tabular}


It is interesting that subjects 1 and 5, who at the first analysis already showed altered levels of modified auto PARP, and a permanent pro-inflammatory FAT Profile, despite the absence of clinical and morphological GI alterations, showed new gastrointestinal diseases. Subject 1 declared foveolar hyperplasia and intestinal metaplasia, but up to the last check on 2015, her endoscopies were negative for neoplasies. Subject 5 developed gastric mucosa dysplasia. Both sisters were positive to $H$. pylorii.

Other subjects developed tumoral forms. On september 2011 brother 2 was diagnosed with a pancreatic head tumor, fatal on october 2011.

On december 2009 sister 3 was diagnosed with a gastric carcinoma; gastric resection followed on January 2010 with degeneration to peritoneal carcinosis and ascites. Meanwhile ovaric carcinoma (Krukhenberg tumor) was discovered and removed. She deceased on June 2010.

Subject 7, who had normal PAR-PARP values, showed new gastrointestinal pathologies, with sigmoid resection (2009) and subsequent colon carcinoma (2012).

No onset of pathologies for subject 8, which however showed alterations in PAR-PARP levels, together with a positive $H$. Pylorii, and to which attention had been paid with more frequent monitoring.

On 2009 sister 9 underwent gastrectomy joint with flogosis and inflammation.

Subject 6, diagnosed with breast cancer on march 2009, underwent mastectomy. On 2013 colon carcioma, and on 2016 pulmonary carcinoma were discovered.

In cases where tumor degenerations had occurred, genetic tests were recommended, in particular performed for patients $6,7,9$.

Subject 6 was investigated for the BRCA1 and BRCA2 genes with a negative result. The analysis highlighted the absence of mutations in the genes investigated, but the tests carried out were not complete, as they lacked the MLPA method, which is able to identify genetic rearrangements that are not detectable with normal sequencing methods (and which, for example, in the case of BRCA1 / 2 genes, are implicated in about $10 \%$ of cases).

Similarly, subject 7, investigated for the CDH1 (E-cadherin) gene, was not positive for mutations; furthermore it was subjected to genetic investigation of the MLH1 and MSH21 genes. The analysis highlighted the absence of mutations in the genes investigated. Mutations in the CDH1 gene are responsible for the hereditary predisposition to gastric cancer and, in women, for lobular carcinoma of the breast.

Subject 9 also gave her informed consent to the mutational analysis of the CDH12 gene, which, however, did not identify pathological changes.

Therefore the genetic investigation discussed here did not confirm the hypothesis of an inherited form of gastric neoplasia. However, the genetic reports do not completely exclude this hypothesis, since there may be mutations in the $\mathrm{CDH} 1$ gene that are not identifiable with the test performed or mutations in unknown genes.

\subsection{Molecular analyses of some young family members}

2.3.1. PAR-PARP. Densitometry of the immunological profiles.

The PAR-PARP analysis was extended to the young members of the family, sons and daughters of people in Table 1.

Figure 3 shows the results of densitometric analyzes at the beginning of the survey, compared with those obtained on 2009. No results are available at later times since all subjects (elderly and young) refused to undergo further molecular analysis. 


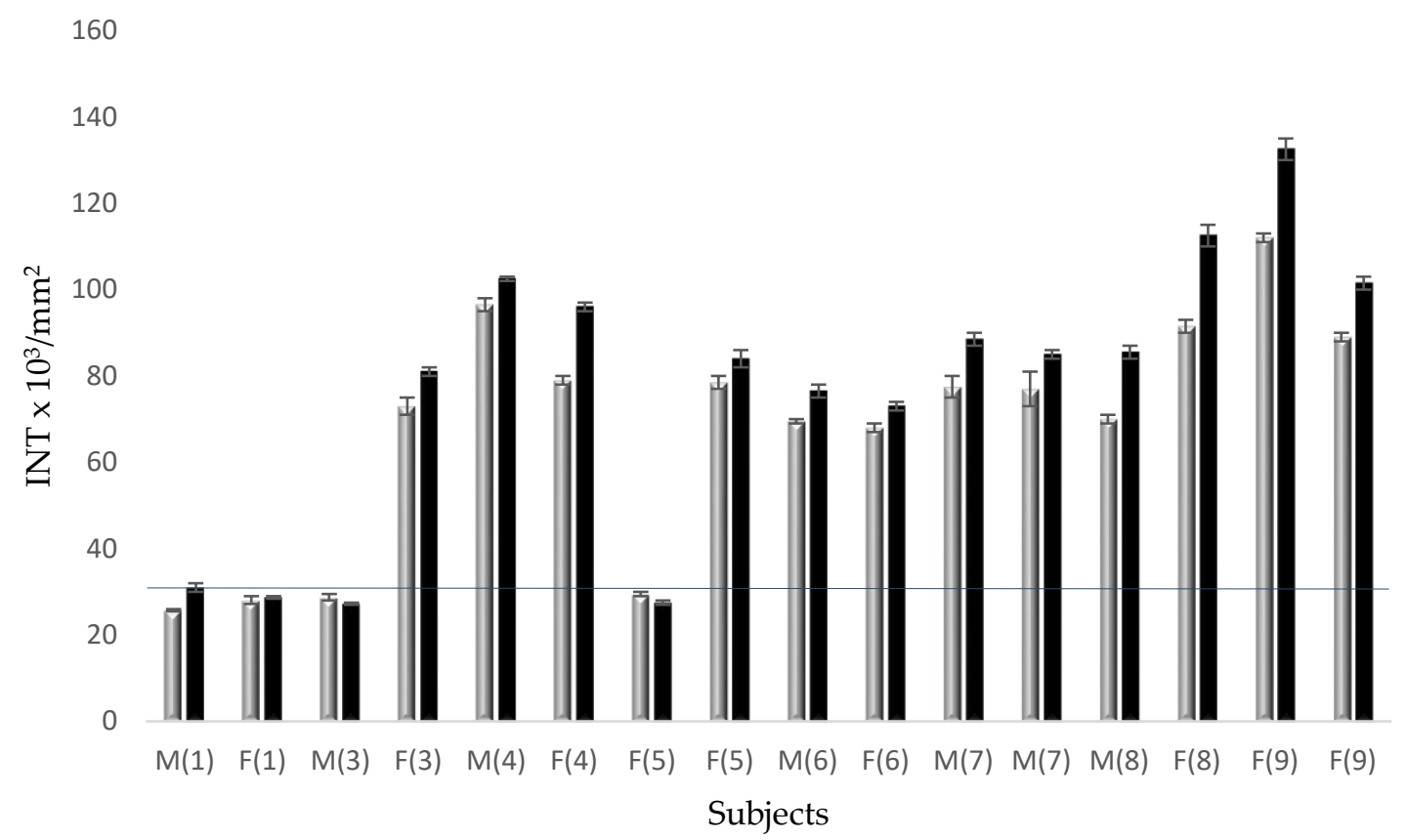

Figure 3. Densitometric analyses of PAR-PARP levels in family's young members, on 2006 (grey) and on 2009 (black). The numbers in brackets correspond to brothers in Table 1. M, male; F, female. The line corresponds to the cut-off value.

Therefore, later on, further information was collected only from the endoscopic analyzes and reported in Figure 4.

Most densitometry values fell in the range of high damage degree (>60 O.D.x103 $/ \mathrm{mm} 2)$, in both analyzes. With the first determination of PAR-PARP it was highlighted that, for subjects who declared no pathology or clinical parameters alteration, the molecular signals suggested a nonphysiological condition, confirmed by the subsequent determination. Only in some subjects the values were around the cut-off in both analyses.

\subsubsection{Anamnestic and clinical data}

Figure 4 shows the clinical condition of young people and allows to correlate it with the PARPARP analysis. There are reported the lineages of each brother with the indication of gender, age (1842 years), and results of the initial and subsequent history, at different times. 


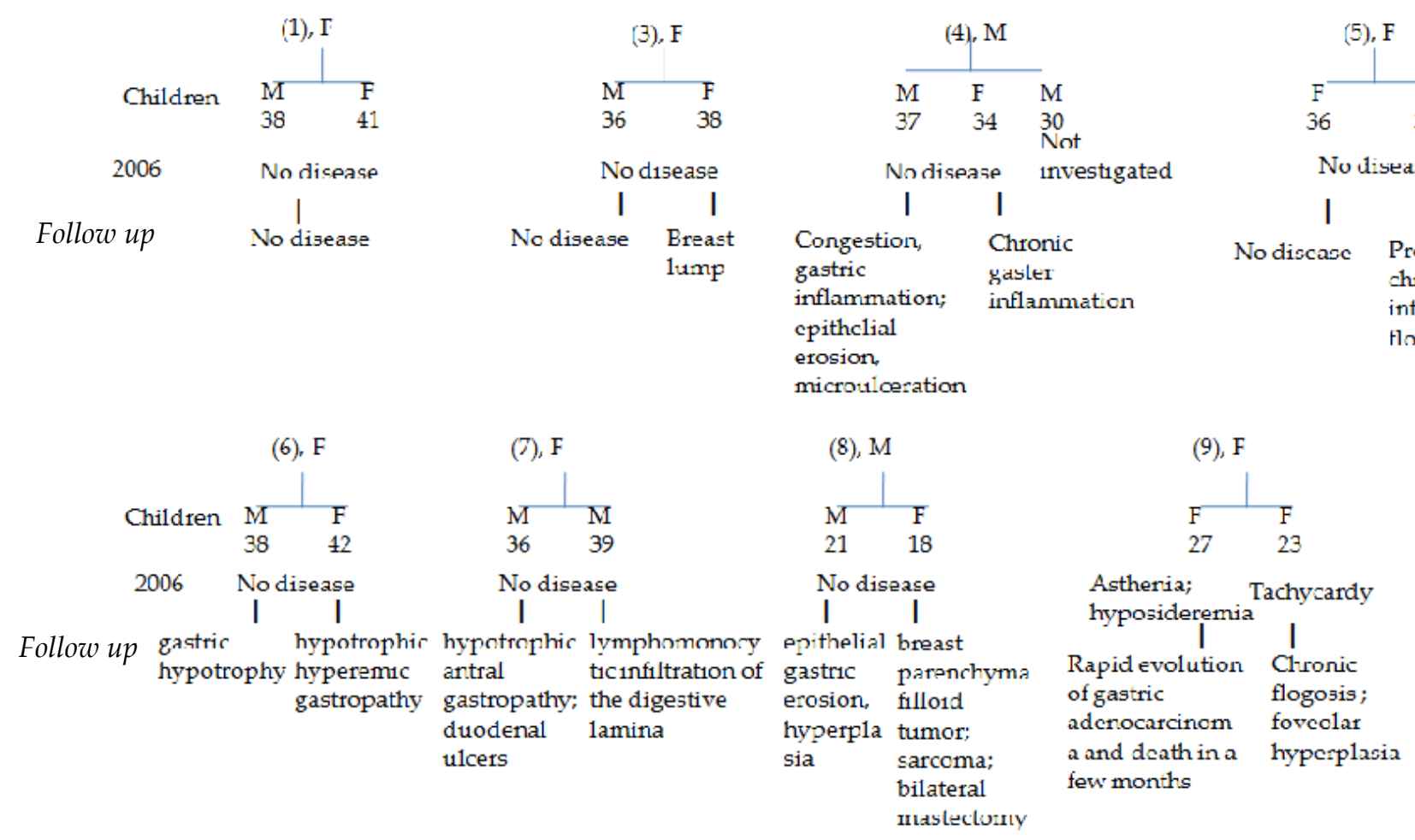

Figure 4. Scheme of development of young people's pathologies from 2006. The numbers in brackets correspond to brothers in Table 1, their parents. M, male; F, female.

The information collected at the beginning of the survey did not indicate the presence of pathologies. All subjects declared themselves healthy, except for one case, subject 9, affected by asthenia and favism, inherited from the Sardinian father, (Figure 4). Favism affected also the other sister.

A subject (not investigated) always refused to undergo endoscopic, clinical and PAR-PARP analysis.

Subsequent endoscopic checks were carried out, in the years of investigation, at different times for all subjects $(n=16)$ adhering to the survey, and with a variable frequency depending on the need of subjects.

Three people showed no onset of pathologies, in particular of the gastrointestinal tract, in line with the values at the cut-off point of Figure 3.

The diagnoses of the remaining patients changed to different degrees of severity (Figure 4). In one case $(\mathrm{F}, 18$, daughter of brother 8$)$, there was a rapid evolution towards tumors (initial filloid tumor at the mammary parenchyma; cellular pleomorphism, sarcoma), which required a bilateral mastectomy on 2017.

Fatal epilogue had the condition of the young woman who initially suffered from asthenia and favism, and, in the earliet years of investigation, developed a gastric adenocarcinoma with very rapid worsening which led to her death in three months. The rapid evolution of the tumor and her great weakness did not allow surgery (Figure 4).

In general, the altered PAR-PARP values corresponded to a pathological severity of the subjects initially declared healthy, of varying degrees up to the tumor forms, with an even lethal outcome (Figure 3).

The results of Figure 3, in many cases, preceded the evidence of worsening of the pathologies diagnosed with endoscopies 


\subsubsection{Lipidomic analysis}

$n 6$ and $n 3$ PUFA profiles of most subjects showed inflammatory conditions, despite all young people declared to be healthy (Table 4$)$. With some exceptions ( $3 \mathrm{M}, 6 \mathrm{~F}, 8 \mathrm{~F}, 8 \mathrm{M}, 9 \mathrm{~F} 23), n 6 / n 3$ ratios of all samples were altered at different levels, but always indicating either an increase of proinflammatory $n 6$ mediators (arachidonic acid) or a deficit of anti-inflammatory $n 3$ compounds (EPA, DHA). The follow up on 2009 (profiles not shown), confirmed this trend. It is worth noting the very high $n 6 / n 3$ unbalance measured for the subject $9 \mathrm{~F}(27)$ (Table 4), the woman who developed a gastric carcinoma and deceased at the end of 2009.

Table 4. $n 6$ and $n 3$ PUFA patterns of offspring blood red cell membrane (2006).

\begin{tabular}{|c|c|c|c|c|c|c|}
\hline Parent $^{a}$ & $\begin{array}{l}\text { Child } \\
\text { (Age) }\end{array}$ & $\begin{array}{c}\text { DGLA (n6) } \\
(\%)^{\mathrm{b}}\end{array}$ & $\begin{array}{c}\text { ARA (n6) }{ }^{b} \\
(\%)^{\mathrm{c}} \\
\end{array}$ & $\begin{array}{c}\text { EPA (n3) }{ }^{b} \\
(\%)^{\mathrm{c}}\end{array}$ & $\begin{array}{c}\text { DHA (n3) }{ }^{b} \\
(\%)^{\mathrm{c}}\end{array}$ & $\begin{array}{l}n 6 / n 3 \\
(\%)^{c} \\
\end{array}$ \\
\hline 1 & M (38) & $1.8(-5.3)$ & $18.4(+8.2)$ & $0.5(0)$ & $4.2(-16)$ & $\begin{array}{c}6.7 \\
(+22.2)\end{array}$ \\
\hline 1 & $\mathrm{~F}(41)$ & $2(0)$ & $20.4(+20)$ & $0.5(0)$ & $5.5(0)$ & $5.7(+3.9)$ \\
\hline 3 & M (36) & $19(0)$ & $17.6(0+3.5)$ & $0.6(0)$ & $6.2(0)$ & $4.5(0)$ \\
\hline 3 & $F(38)$ & $2.6(+8.3)$ & $18.2(+7)$ & $0.4(-20)$ & $3.9(-22)$ & $7.6(+38)$ \\
\hline 4 & M (37) & $1.6(-15.8)$ & $18.5(+8.8)$ & $0.3(-40)$ & $3.6(-28)$ & $8.3(+50)$ \\
\hline 4 & F (34) & $1.9(0)$ & $21.3(+25.3)$ & $0.5(0)$ & $5.2(0)$ & $\begin{array}{c}6.5 \\
(+18.3)\end{array}$ \\
\hline 5 & F (36) & $2.1(0)$ & $21.2(+24.7)$ & $0.4(-20)$ & $4.5(-10)$ & $\begin{array}{c}7.0 \\
(+24.7)\end{array}$ \\
\hline 5 & $\mathrm{~F}(34)$ & $2(0)$ & $19.5(+14.7)$ & $0.4(-20)$ & $4,2(-16)$ & $\begin{array}{c}7.35 \\
(+33.6)\end{array}$ \\
\hline 6 & M (38) & $2.1(0)$ & $18(+4)$ & $0.3(-40)$ & $2.9(-42)$ & $10(+83)$ \\
\hline 6 & $\mathrm{~F}(42)$ & $1.9(0)$ & 19 (11.8) & $0.6(0)$ & $5.4(0)$ & $5.5(0)$ \\
\hline 7 & M (39) & $2(0)$ & $18.6(+9.4)$ & $0.5(0)$ & $5(0)$ & $\begin{array}{c}6.2 \\
(+13.3)\end{array}$ \\
\hline 7 & M (37) & $2(0)$ & $18.5(+9.4)$ & $0.3(-40)$ & $4.7(-6)$ & $\begin{array}{c}6.8 \\
(+23.3)\end{array}$ \\
\hline 8 & M (21) & $2.2(0)$ & $17(0)$ & $0.6(0)$ & $5.2(0)$ & $5.5(0)$ \\
\hline 8 & F (18) & $1.9(0)$ & $19(+12)$ & $0.6(0)$ & $5.4(0)$ & $5.45(0)$ \\
\hline 9 & $\mathrm{~F}(23)$ & $1.5(-21.0)$ & $18.5(+8.8)$ & $0.7(0)$ & $5.7(0)$ & $5.2(0)$ \\
\hline 9 & $\mathrm{~F}(27)$ & $1.9(0)$ & $18.5(+8.8)$ & $0.3(-40)$ & $3.7(-26)$ & $\begin{array}{c}8.6 \\
(+56.8) \\
\end{array}$ \\
\hline
\end{tabular}

aBrothers in Table 1.

b Total Lipid (\%)

In brackets, unbalance \%.

\section{Materials and Methods}

\subsection{Patients}

The patients object of this survey belonged to the same family (the oldest were 9 people, all brothers; the youngest, their descendants), monitored from May 2006 to December 2017. They all signed an informed consent for anonimous treatment of their data, according to the rules about privacy. Authorization ( $\left.\mathrm{N}^{\circ} 131 / 11\right)$ for this clinical trial was obtained from the ethics Committee "C. Romano" for biomedical activities. Each of the nine brothers was identified with a number, ordered from the oldest to the youngest subject. The descendants were identified with a capital letter $(\mathrm{M}$, 
male; F, female) followed by the number corresponding to the parent (one of the brothers), in brackets. All subjects were periodically invited to the Diagnostic Laboratory "Filippo Bottazzi" of Azienda Sanitaria Locale 5 (ASL NA5, nowadays renamed ASL NA3 sud, District 57), in Torre del Greco, a town in the sorrounding of Naples, Italy, for interview and blood collection by venepuncture. Over survey time, some patients refused to undergo molecular analyses again. Thus, only two complete sets of results were performed.

As a control group 30 anonimous volunteers were selected among habitual donors at the transfusional Center of the Hospital "Agostino Maresca" (ASL NA3, Torre del Greco); their blood samples were provided with results of routine clinical analyses. These subjects were defined "healthy" and suitable as blood donors as they did not suffer any serious disease and gave clinical results within the normal range of values. This group enclosed also those people giving responses to our specific analyses within values enclosed in normal ranges, but at upper limit.

\subsection{Blood collection and treatment}

Blood $(15 \mathrm{ml})$ was collected by venepuncture in the presence of EDTA and aliquoted. Samples were stored at $4^{\circ} \mathrm{C}$ until use. One aliquot $(5 \mathrm{ml})$ was used to define the clinical state of each subject; the other aliquots $(5 \mathrm{ml})$ were used to prepare lymphocyte and erythrocyte fractions.

Routine clinical analyses (azotemia, cholesterolemia, glicemia, triglyceridemia, transaminases, hemochrome, serum proteins, etc.) were performed at "F. Bottazzi" laboratory, where lymphocyte fraction for PARP analysis was prepared within two hours from blood uptake, to avoid hemolysis. Erythrocyte fraction was prepared at Lipinutragen laboratory (Bologna, Italy) [19].

\subsection{Lymphocyte preparation and lysis.}

All operations were performed at $4^{\circ} \mathrm{C}$. Three to five blood aliquots $(1 \mathrm{ml})$ of each sample were separately used to prepare lymphocytes according to [27], after counting the cells per blood $\mathrm{ml}$ by hematic cell counter. In this way taking into account a comparable loss of lymphocytes during preparation under the same conditions for all samples, the results were referred to the initial number of cells $/ \mathrm{ml}$.

Preparing lymphocytes, briefly each blood aliquot $(1 \mathrm{ml})$ was layered on a Ficoll-Hypaque (GE Healthcare) cushion (1: 0.7, v/v) and centrifuged at 2,500 rpm for 10 minutes. Crude lymphocyte fraction was washed twice with $0.9 \% \mathrm{NaCl}$, followed by 10 ? min centrifugation at $1,500 \mathrm{rpm}$. Pelleted pure lymphocytes were suspended in $0.9 \% \mathrm{NaCl}(100 \quad 1 / \mathrm{blood} \mathrm{ml})$. Few microliters of the suspension were used for counting pure lymphocytes. In general a $20 \%$ loss was measured.

Pure lymphocytes were often used as freshly prepared fraction or stored at $-80^{\circ} \mathrm{C}$ until used.

Cells from $1 \mathrm{ml}$ blood were lysed by suspension in lysis buffer $(300 \mu \mathrm{l} ; 10 \mathrm{mM}$ Tris- $\mathrm{HCl} \mathrm{pH} 7.5$, 1\% Nonidet P40, 2mM Spermidine- $\mathrm{HCl}, 10 \mathrm{mM}$ Na2EDTA, protease inhibitor cocktail $(2 \mu \mathrm{g} / \mathrm{ml}$; Sigma, Milan), 1mM Phenyl Methyl SulphonylFluoride, PMSF), and incubated for 30 minutes at $4^{\circ} \mathrm{C}$. The whole lysate was further analysed.

Protein content was determined byBradford's reagent (BioRad) according to the provided instructions. DNA damage in some samples was assayed by Comet assay procedure [29].

\subsection{SDS-PAGE and western blotting}

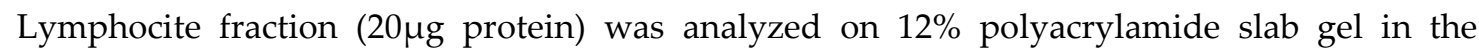
presence of $0.1 \%$ SDS according to [27]. Gels were stained in $0.1 \%$ Coomassie G in $10 \%$ acetic acid/ $30 \%$ methanol. For immunoblotting electrophoresed proteins were transferred onto polyvinylidene fluoride (PVDF) membrane (Biorad) at $200 \mathrm{~V}$ for $1.5 \mathrm{~h}$ at $4^{\circ} \mathrm{C}$ in the same buffer used for electophoretic run (Faraone Mennella et al. 2009). For immunoblot experiments procedures and buffers were according to [27] and references therein. PVDF sheets were treated for $1.5 \mathrm{~h}$ with blocking solution (50mM Tris- $\mathrm{HCl}$ buffer, $\mathrm{pH} 8.0 ; 150 \mathrm{mM} \mathrm{NaCl} ; 0.5 \%(\mathrm{v} / \mathrm{v})$ Tween 20 and $3 \%$ gelatine). Incubation with commercial polyclonal anti-PARP 1 (Santa Cruz Biotechnology, 
Heidelberg, Germany), was performed for $2 \mathrm{~h}$ at room temperature in the same solution supplemented with $0.3 \%$ gelatine. The filter was washed several times with TBS-Tween and antibody binding was detected by using anti-mouse $\operatorname{IgG}(\mathrm{H}+\mathrm{L})$ horseradish peroxidase $(1: 1000, \mathrm{v} / \mathrm{v})$. The reaction was revealed by using a kit for chemiluminescence (Super signal West Dura, Extended Substrate, Pierce Manufacturing Inc. US) and reading by a Quantitaty One program in a Chemidoc apparatus (Bio-Rad, Segrate, Milan, Italy).

\subsection{Erythrocyte membrane fatty acid determination}

An aliquot $(1 \mathrm{ml})$ of each blood sample was used for the fatty acid analysis of erythrocyte membrane performed by the procedure described in [30 - 32].

This procedure is effected by an automatism set up at Lipinutragen [31], a spin-off company of the National Council of Research (CNR) in Bologna (Italy), connected with the calculation of the membrane unbalance index. The membrane fatty acid cluster used in the analysis is made of ten cisfatty acids and two trans fatty acids [31]. This analysis is commercialized as FAT PROFILE ${ }^{\circledR}$.

\section{Conclusions}

This work done in the peculiar context of a family with gastro-intestinal and cancer disease development points attention to two non-invasive blood tests checking specific molecular indicators in two cellular compartments, in particular concerning DNA protection and cell membrane balance given by the hydrophobic fatty acid residues. The DNA-membrane correspondence has been demonstrated recently in tumor-bearing mice using purine-5',8-cyclonucleosides, as the DNA damage biomarker, together with lipidomic profiles [32], and is a promising multidisciplinary approach to cancer. PARP automodification and membrane fatty acid balance alteration checked in the family members along a time frame of more than 10 years evidenced the early response of these two indicators, with high PARP automodification and pro-inflammatory molecular profiles in apparently healthy individuals that later on developed cancer and had lethal events. Further work in large cohorts is needed, also in view of the application of anti-inflammatory and nutrition-based strategies to follow-up the individuated biomarkers. This work foresees the efficiency of the DNAmembrane investigation also as preventive strategy for re-establishing control of cellular damages.

Supplementary Materials:The following are available online, Table S1: Altered Hematic Parameters of brothers, starting the survey in 2006; § S2.2.1: Densitometric analysis and methods of result evaluation; Figure S1: Scheme of PARP 1 and 2 immunoblotting; § S2.2.2: SDS-PAGE and immunoblotting of control lymphocyte extracts; Figure S2: SDS-PAGE and immunoblotting of control lymphocyte extracts; Figure S3: Immunoblotting of nine brothers' lysates (analysis 2009); § S2.3: Fat Profile; Table S3: Fat Profiles of the elderly members (2006).

Author Contributions: conceptualization, C.F. and M.R.F.M..; methodology, C.F., E.C., A.D.M. and M.M; formal analysis, C.F., E.C., A.D.M. and M.M.; investigation, E.C.; resources, C.F., C.C. and M.R.F.M.; writing-original draft preparation, M.R.F.M..; writing - review and editing, C.F, M.R.F.M.and C.C..; supervision, C.F., C.C. and M.R.F.M; funding acquisition, M.R.F.M.

Funding: This work received the financial support of Regione Campania, Italy (Projects N ${ }^{\circ}$ L5/2003 and 2007).

Acknowledgments: We wish to thank Dr Filippo Figalli, head of the transfusional Centre of the Hospital “A. Maresca” (Torre del Greco) for providing control samples. We are grateful to Dr Claudio Bufi, past head of the Laboratory "F.Bottazzi", to members of the staff, Drs G. Di Bernardo, G. Di Giacomo and T. Sollo for technical support and use of the ASL laboratory, and to the nurse, Mrs Maria Cirillo for assistance in blood sampling. 
Conflicts of Interest: CF and CC are co-founders of the company Lipinutragen srl which is involved in commercial use of the membrane lipidomic analysis. The other authors declare no conflict of interest.

\section{References}

1 Holtmann, G.;' Shah, A.;' Morrison M. Pathophysiology of Functional Gastrointestinal Disorders: A Holistic Overview Dig Dis 2018, 35(1), 5-13.

2 Frank, T.S. Hereditary Cancer Syndromes. Arch Pathol Lab Med 2001, 125, 85-90.

3 Stadler, Z.K.; Schrader, K.A.; Vijai, J.; Robson, M.E.; Offit, K. Cancer Genomics and Inherited Risk. J Clin Onc 2014, 32, 687-698. doi:10.1200/jco.2013.49.7271

4 Chintalacheruvu; L.M.; Shaw, T.; Buddam, A.; Linch, H.T. Major hereditary gastrointestinal cancer syndromes: A narrative review. JGLD 2017, 26(2), 157-163.

5 Venkata, S.; Katabathina, C.; Menias, O.; Khanna, L.; Murphy, L.; Dasyam, A.K.; Lubner, M.G.; Prasad, S.R. Hereditary Gastrointestinal Cancer Syndromes: Role of Imaging in Screening, Diagnosis, and Management. RadioGraph 2019,. 39, 5.

6 Yousefi, M.S.; Sharifi-Esfahani, M.; Pourgholam-Amiji, N.; Afshar, M.; Sadeghi-Gandomani, H.; Otroshi, O.; Salehiniya H. Esophageal cancer in the world: incidence, mortality and risk factors. Biom Res Ther 2018, 5(7), 2504-2517.

7 Polk, D.B.; Peek, R.M. Helicobacter pylori: gastric cancer and beyond. Nat Rev Cancer. 2010, 10(6), 403-414. doi:10.1038/nrc2857;

8 Díaz,P.; Valenzuela Valderrama, M.; Bravo, J.; Quest, A.F.G. Helicobacter pylori and Gastric Cancer: Adaptive Cellular Mechanisms Involved in Disease Progression. Front. Microbiol 2018 | https://doi.org/10.3389/fmicb.2018.00005

9 Romeo, S.; Debiec-Rychter, M.; Van Glabbeke, M.; Van Paassen, H.; Comite, P.; Van Eijk, R.; Oosting, J.; Verweij, J.; Terrier, P.; Schneider, U.; Sciot, R.; Blay J.Y.; Hogendoorn,P.C.W. Cell Cycle/Apoptosis Molecule Expression Correlates with Imatinib Response in Patients with Advanced GastrointestinalStromal Tumors. Clin Cancer Res 2009, 15(12).

10 Chaitanya, G.V.; Alexander, J.S.; Prakash Babu, P. PARP-1 cleavage fragments: signatures of cell-death proteases in neurodegeneration. Cell Commun Signal 2010, 8, 31.

11 Faraone Mennella, M.R. Mammalian Spermatogenesis, DNA Repair, Poly(ADP-ribose) Turnover: the State of the Art- In: On the Pathways to Fixing DNA Damage and Errors, Storici, F., ed., InTech, 2011, .235-254. doi: 10.5772/23337;

12 Hottiger, M.O. Nuclear ADP-Ribosylation and Its Role in Chromatin Plasticity, Cell Differentiation, and Epigenetics. Ann Rev Biochem 2015, 84,227-263.

13 Rodríguez-Vargas, J.M.; Oliver-Pozo, J.O.; Dantzer, F. PARP1 and Poly(ADP-ribosyl)ation Signaling during Autophagy in Response to Nutrient Deprivation. Oxid Med Cell Longev 2019, Article ID 2641712. https://doi.org/10.1155/2019/2641712

14 Lin, K.Y.; Huang, D.; Kraus, W.L. Generating Protein-Linked and Protein-Free Mono-, Oligo-, and Poly(ADP-Ribose) In Vitro. Meth Mol Biol. 2018, 1813:91-108. doi: 10.1007/978-1-49398588-3_7.

15 Bonicalzi, M.E.; Vodenicharov,M.; Coulombe, M.; Gagné, J.P.; Poirier. G.G. Alteration of poly(ADP-ribose) glycohydrolase nucleocytoplasmic shuttling characteristics upon cleavage by apoptotic proteases. Biol Cell 2003, 95, 635-644.

16 Pedrioli, D.M.L.; Leutert, M.; Bilan, V.; Nowak, K.; Gunasekera, K.; Ferrari, E.; Imhof, R.; Malmström, L.; Hottiger,M.O. Comprehensive ADP-ribosylome analysis identifies tyrosine as an ADP-ribose acceptor site. EMBO Rep 2018, 19, e45310; doi.org/10.15252/embr.201745310.

17 Bai, P.; Cantò, C. The Role of PARP-1 and PARP-2 Enzymes in Metabolic Regulation and Disease. Cell Metab 2012, 16(3), 290-295.

18 Conrad, L.B.; Lin, K.Y.; Nandu, T.; Gibson, B.A.; Lea, J.S.; Kraus, W.L. ADP-ribosylation Levels and Patterns Correlate with Gene Expression and Clinical Outcomes in Ovarian Cancers. Mol Cancer Ther 2019, pii: molcanther.0569.2019. doi: 10.1158/1535-7163.MCT-19-0569. 
19 Ferreri, C.; Chatgilialoglu, C: Role of fatty acid-based functional lipidomics in the development of molecular diagnostic tools. Expert Rev. Mol. Diagn. 2012, 12, 767-780.

20 Smilowitz, J.T.; Zivkovic, A.M.; Wan, Y.J.; Watkins, S.M.; Nording, M.L.; Hammock, B.D.; German, J.B. Nutritional lipidomics: molecular metabolism, analytics, and diagnostics. Mol Nutr Food Res 2013, 57, 1319-1335.

21 Wang, X.; Lin, H.; Gu, Y. Multiple roles of dihomo- - -linolenic acid in proliferation diseases. Lipids Health Dis 2012, 11, 25 http://www.lipidworld.com/content/11/1/25

22 Chatgilialoglu, C.; Ferreri, C: Nutrilipidomics: A Tool for Personalized Health. J. Glycom Lipidom 2012, 2, e109(2012).

23 Calder, P.C. Polyunsaturated fatty acids and inflammatory processes: New twists in an old tale. Biochimie 2009, 91, 791-795.

24 Kiss, B.; Szántó, M.; Szklenár, M.; Brunyánszki, A.; Marosvölgyi, T.; Sárosi, E.; Remenyik, E.; Gergely, P.; Virág, L.; Decsi, T.; Rühl, R.; Bai P. Poly(ADP-ribose) polymerase-1 ablation alters eicosanoid and docosanoid signaling and metabolism in a murine model of contact hypersensitivity. Mol Med Rep 2015, 11(4), 2861-2867.

25 Faraone-Mennella, M.R.; Masi, A.; Ferreri, C. Regulatory Roles of PARP-1 and Lipids in Epigenetic Mechanisms. In: Handbook of Nutrition, Diet, and Epigenetics; Patel V., Preedy V., Eds. Springer, Cham, 2017; doi.org/10.1007/978-3-319-31143-2_37-1

26 Sansone, A.; Tolika, E.; Louka, M.; .; Sunda, V.; Deplano, S.; Melchiorre, M.; Anagnostopoulos, D.; Chatgilialoglu, C.; Formisano, C.; Di Micco, R.; Faraone Mennella, M.R.; Ferreri, C. Hexadecenoic Fatty Acid Isomers in Human Blood Lipids and Their Relevance for the Interpretation of Lipidomic Profiles. PLOS One 2016, 11(4), e0152378. doi: 10.1371/journal.pone.0152378.

27 Imperato, S:; Mistretta, C.; Marone, M; Migliaccio, I.; Pulcinelli, I.; Faraone Mennella, M.R. Automodified Poly(ADP-Ribose) Polymerase Analysis to Monitor DNA Damage in Peripheral Lymphocytes of Floriculturists Occupationally Exposed to Pesticides. Cells 2019, 8(2), 137. doi: $10.3390 /$ cells8020137

28 Bianchi, A.R.; Ferreri, C.; Ruggiero, S.; Deplano, S.; Sunda, V.; Galloro, G.; Formisano, C.; Faraone Mennella, M.R. Automodification of PARP and fatty acid-based membrane lipidome as a promising integrated biomarker panel in molecular medicine. Biomark Med. 2016, 10(3), 229242.

29 D'Onofrio, G.; Tramontano, F.; Dorio, A.S.; Muzi, A.; Maselli, V.; Fulgione, D.; Graziani, G; Malanga, M.; Quesada, P. Poly(ADP-ribose) polymerase signaling of topoisomerase 1-dependent DNA damage in carcinoma cells.Biochem. Pharmacol. 2011, 81, 194-202.

30 Ferreri, C.; Chatgilialoglu, C. Membrane Lipidomics for Personalized Health, Wiley and Sons:New York, 2015.

31 Ferreri, C.; Masi, A.; Sansone, A.; Giacometti, G.; Larocca, A.V.; Menounou, G.; Scanferlato, R.; Tortorella, S.; Rota, D.; Conti, M.; Deplano, S.; Louka, M.; Maranini, A.R.; Salati, A.; Sunda, V.; Chatgilialoglu, C. Fatty acids in membranes as homeostatic, metabolic and nutritional biomarkers: recent advancements in analytics and diagnostics. Diagnostics 2017, 7(1); doi:10.3390/diagnostics7010001.

32 Krokidis, M.G.; Louka, M.; Efthimiadou, E.K.; Zervou, S.K.; Papadopoulos, K.; Hiskia, A.; Ferreri, C.; Chatgilialoglu, C. Membrane Lipidome Reorganization and Accumulation of Tissue DNA Lesions in Tumor-Bearing Mice: An Exploratory Study. Cancers 2019, 11, 480. 